\title{
Between elderly parents and adult children: a new look at the intergenerational care provided by the 'sandwich generation'
}

\author{
EMILY GRUNDY* and JOHN G. HENRETTA $†$
}

\begin{abstract}
The 'sandwich generation' has been conceptualised as those mid-life adults who simultaneously raise dependent children and care for frail elderly parents. Such a combination of dependants is in fact very unusual, and the more common situation is when adults in late mid-life or early old age have one or more surviving parents and adult but still partly dependent children. It can be hypothesised that for parents in this pivotal position, the demands from adult children and from elderly parents compete, with the result that those who provide help to one are less likely to provide help to the other. An alternative hypothesis, however, is that family solidarity has an important influence but is not universal, so that some pivotal-generation parents engage in intergenerational exchange in both directions, and there is a positive association between helping parents and helping children. To investigate this question, the paper presents an analysis of data from two broadly comparable national surveys, in Great Britain and the United States, on the care provided by women aged $55^{-69}$ years to their descendent and ascendent relatives. The results show that around one-third of the women reported providing help to members of both generations, and that around one-fifth provided support to neither. They broadly support the solidarity hypothesis, but provide some evidence that having three or more children is associated with a reduced likelihood of providing help to a parent.
\end{abstract}

$\boldsymbol{K E Y} \boldsymbol{W} \boldsymbol{W} \boldsymbol{D} \boldsymbol{S}$ - intergenerational support, exchanges, three-generation families, UK, USA.

\section{Introduction}

The demographic changes that have resulted in population ageing in all developed countries and a rising number of less-developed countries have been accompanied by changes in the structure and size of kin networks (Wolf i994). These include the 'verticalisation' of family structures

* Centre for Population Studies, London School of Hygiene and Tropical Medicine, UK.

$\dagger$ Department of Sociology, University of Florida, Gainesville, Florida, USA. 
(Bengtson, Rosenthal and Burton 1990) and the increased prevalence of families with three, four and even five living generations. As some analysts have noted, the extent of strong vertical links (at the expense of extended same-age or same-generation links) may not be as great as some claim, because the continuing decline in late-age mortality may have been offset by decreased and delayed fertility. If this is so, and if these trends continue, there will be longer gaps between the generations, and the prevalence of four- and five-generation families may increase more slowly than has been anticipated (Farkas and Hogan 1995). Nevertheless, recent demographic modelling in Britain suggests that the proportion of women aged 6o-69 years with a mother still alive will continue to increase until those born during the I97os reach this age (Murphy and Grundy 2003). If four- and five-generation families remain comparatively rare, families with three living generations are common. A recent British survey, for example, found that 80 per cent of 20-year-olds had at least one grandparent alive, and that most adults were members of a family with three living generations (Grundy, Murphy and Shelton 1999). This proportion was in fact lowest among those aged 50-59 years, among whom the births of grandchildren had not compensated for the deaths of parents, but one-half of those aged 50 years still had a parent alive.

These changes in the demographic structure of families have important implications for family behaviour. While divorce and low fertility may reduce the centrality of the nuclear family, the increase in the number of generations alive at any one time, and the 'longer years of shared lives', increase concomitantly the importance of extended family relationships (Hogan, Eggebeen and Clogg I993; Bengtson 200I). While this insight has spawned several studies of the relationships between two generations, it also provides a strong rationale for giving attention to the relationships within three or more extant-generation families.

Much of the current research and policy interest in three-generation families has been on women in a broad age group, late-middle age, because of the possibility that they experience the simultaneous responsibilities of caring for elderly parents and children (Brody I98i ; Soldo I996). The 'sandwich generation' concept, of parents raising dependent children while also having parents in need of support, has resonated widely, as attested by the many dedicated websites and support groups, particularly in the United States (e.g. http://www.empub.com/sandwichgen.shtml). The configuration requires, however, either later-than-average childbearing in two successive generations, or the unusually early onset of disability in the oldest generation. The study by Agree, Bissett and Rendall (2003) found, for example, that among British women during the I99os, the 
proportion that provided care for an elderly parent or parent-in-law peaked (at I9\%) among those aged 50-54 years, but that only i3 per cent of this age group still had a co-resident child aged under i8 years; as a result, only two per cent provided care for a parent and lived with a dependent (or minor) child.

Much more common are families in which the potential call for simultaneous support comes from adult but still partly dependent children and from elderly parents. Adults, particularly women, in late-middle age are the most likely to face these two-way commitments; in the French literature they have been termed the 'pivot generation' on whom family relationships turn (Attias-Donfut 1995). Several changes in socio-economic and cultural parameters may be raising young adults' need for parental support, notably the extension of full-time education and delay of their financial and household independence, the increasing impediments to their economic independence, and the increased incidence of divorce and partner estrangement (Goldscheider and Goldscheider 1994; Berthoud and Gershuny 2000). These, in turn, have increased the demands on the pivot-generation parents, who must also safeguard their financial resources for their own retirement.

\section{Demands on the pivot generation and their patterns of help}

A central issue in the situation of the three-generation configuration is how the pivot generation resolves conflicting expectations from the ascendent and descendent generations. Instrumental help, as with money or time spent on household and personal tasks, is critical because - unlike emotional closeness - these resources are finite, and those given to one generation cannot be given to the other or retained. Studies of relationships between two generations - older people and their adult children have found that a minority of families are 'high exchangers'. Silverstein and Bengtson (1997) distinguished several family types that they had observed cross-sectionally: 'tight-knit' families, about one-quarter of their sample, were close on several dimensions and both gave and received much instrumental assistance, while the other family types engaged less or not at all in instrumental exchange. Hogan, Eggebeen and Clogg (I993) produced a lower estimate of the prevalence of 'high exchangers' (circa II \%).

Patterns of instrumental help among family members become more complex when three generations are involved, self-evidently because each generation may give to as well as receive from two other generations. To simplify matters, we focus on the donor behaviour of the middle or 
'sandwich' generation. How do mid-life adults divide their efforts between helping elderly parents and adult children? Does the provision of help to parents reduce the likelihood of helping children (and vice versa)? That is, are the patterns of help consistent with the hypothesis of competing demands, which suggests a negative relationship between the two types of help, or the alternative hypothesis of family solidarity, which suggests a positive relationship?

It is argued that the 'tight-knit' and 'high-exchanger' family types identified in previous research on two generations can be extended to multiple generations, so that those who help the ascendent generation will also help the descendent generation and vice versa. The extension of the hypothesis of family solidarity implies that families differ in their commitment to intergenerational exchange and solidarity: those with the strongest solidarity tend to assist both generations rather than prioritising recipients, while those with low solidarity are least likely to help multiple generations. The alternative hypothesis is that members of the middle generation respond to concurrent demands from elderly parents and adult children by prioritising the needs of one over the other, i.e. they concentrate on helping one generation. Previous research has found a high prevalence of only assisting children, and it has been proposed that children are more likely to be favoured than parents because the norms governing parental responsibility to children are more clearly defined than normative obligations toward parents (Wong, Capoferro and Soldo I999).

Both hypotheses derive from and are extensions of established propositions about the high-exchangers of instrumental help in two-generation relationships. Instrumental help might be directed to only one generation but still qualify as high-exchange in a two-generation analysis. The implication is that concurrent instrumental help for two generations is a particular type of high-exchange behaviour. Demographic change has raised the proportion of families in which patterns of assistance to multiple generations are possible, but the extent to which it occurs has not been well established.

In this paper, we investigate whether transfers from adults in late midlife to elderly parents are positively or negatively associated with transfers to adult children, by analysing data from comparable nationallyrepresentative British and American surveys. The two-country comparison allows us to examine the direction of the association, and the factors that associate with exchanges, in different demographic and policy environments. Both the USA and Great Britain have ageing populations, but the process is further advanced in Britain, where fertility rates are lower and a higher proportion of the population is in the elderly and very 
old age groups. Late-life mortality is lower in the USA, however, so more of those in late mid-life still have a living parent, and the proportion of late mid-life women with both a parent alive and at least one child is much higher (Henretta, Grundy and Harris 200I).

The United Kingdom government has recently withdrawn several supports for young adults, including student grants (replaced by loans), and social-security benefits for $16-18$ year-olds not in work. On the other hand, there is more state support than in the USA for adults aged i8 or more years, e.g. income-support for those not in work; child benefits; allowances and tax credits for low-income working parents; loneparent allowances; entitlements to housing and rent subsidies; and, of course, free-at-the-point-of-delivery health care. This suggests that pivotgeneration parents may be called upon to give more help to young adult children in the USA than in Great Britain, particularly as they have more children and the rates of divorce are higher. If so, this would mean that the 'competition' between the demands of adult children and those of elderly parents is greater in the USA than in Great Britain.

The nationally-representative surveys collected broadly comparable information on kin networks and transfers of various kinds. The analysis reported here builds on earlier comparative work that has examined the differentials, both between the USA and Great Britain and among socioeconomic groups, in the proportion of mid-life adults with living children and living parents (Henretta, Grundy and Harris 2002). This showed that socio-economic advantages were associated with a greater chance of having a living parent but a lower chance of having a child. Variations in the propensity of late mid-life women to provide help to adult children were also examined, and it was shown that high parental income and high educational status were positively associated with financial help to children, especially from married parents, as is congruent with other evidence. This research also showed that among fathers, poor health negatively associated with their provision of help with money and domestic chores, and that among widowed and divorced mothers, poor health reduced their help with domestic chores. The British data showed a strong reciprocal pattern of intergenerational exchange, again congruent with other evidence, and also suggested that there were socio-economic differences in the net upward or downward transfers in two-generation exchanges, e.g. more advantaged mid-life parents gave more to children but received less from them (Grundy 2005). Here we draw on the same data sets but focus on women aged 55-69 years who had at least one (adult) child and at least one living parent or parentin-law, and on the variations in the exchanges among three-generation families. 


\section{Data and methods}

The British data are from the Retirement and Retirement Plans Survey (RS) of I988, and the American from the fourth wave of the Health and Retirement Study (HRS) in I998. The British survey was carried out by the Office for Population Censuses and Surveys (OPCS, now part of the Office for National Statistics (ONS)). The sample included 3,543 randomly-selected 55-69 year-olds (born I9I9-I933), and the response rate was 75 per cent, similar to that achieved in most official surveys in Great Britain (Bone et al. 1992). The response rates achieved by the I998 HRS for the 1924-30, I93I-4I and I942-47 birth cohorts were respectively 72, 84 and 70 per cent (US Health and Retirement Study 2004). The data from both surveys were weighted to their respective population proportions.

\section{Data on the provision of help}

The British survey asked respondents, 'Nowadays/do you/does either of you/regularly or frequently do any of the things on this card for your/ child(ren)/parent? The itemised activities were: providing or cooking meals; washing, ironing or cleaning; shopping; giving lifts in your car; looking after children; helping to sort out paperwork, like financial or legal affairs; decorating, gardening or house repairs; helping with money; and anything else. The HRS asked about three types of help; financial help (gifts of $\$ 500$ or more in the past two years from the couple to a child(ren); the same to parents or parents-in-law; help with looking after grandchildren (whether the respondent and spouse together gave at least Ioo hours per year care to all grandchildren); and help to parents or parentsin-law with chores or with the Activities of Daily Living (ADLs). For the questions on chores and ADL help, which were asked separately, the respondent was asked whether he or she-or married respondents together-gave at least Ioo hours per year in help with either ADL or chores to parents or parents-in-law. The specified types of help differed in the surveys, but as the research question being addressed is whether there was a positive or a negative association between helping children and helping parents, this is not a major limitation.

The covariates to be examined in the analysis were indicated by previous findings on the factors that associate with upward or downward transfers. They include socio-demographic indicators (respondent's age and marital status); socio-economic indicators: the logarithm of income (equivalised for household size in the British data), previous or past occupation (non-manual, manual, occupation missing), and the respondent's disability status. Items on the characteristics of children include: number 
of children (I, 2 or 3 or more), whether any children were aged less than 25 years, and whether any lived with the respondent. Not surprisingly, there were differences between the two surveys in the definition of several of the required variables, but in most cases it was possible to derive comparable indicators.

Measures of occupational status and disability status differed most. The British RS collected full occupational histories from all respondents, while the US HRS asked only about current occupation or last occupation during the previous 20 years, so was not available for some io per cent of the female sample. On disability, the RS collected detailed data using various scales first developed for the I986/7 OPCS surveys of disability (for details see Martin and Elliot I992; Disney et al. I997). Here we use a 'severity of disability' score to classify respondents as having no ('o'); mild (' I-3'); or moderate-to-severe disability ('4-IO'). The US disability questions were less extensive and based on questions about mobility. The respondents were categorised as 'free of disability' if they had no difficulty in walking several city-blocks or several flights of stairs; as having 'some disability' if they had difficulty in walking either several blocks or several flights of stairs, and as having 'serious disability' if they had difficulty in walking one block or one flight of stairs. The analysis does not include measures of the parents' or children's needs because the British data had no such data. No measure of residential proximity was included, because living near a parent or child may be the result of a plan to help that family member. In the literature on residential mobility, for example, both conceptual arguments (Litwak and Longino I987) and empirical results (Speare, Avery and Lawton I99I) indicate that when their health declines, there is a tendency for older people to move to be near to or to co-reside with others, usually family members.

The analyses were restricted to women, both because it was assumed that women have more involvement in care than men and would be most influenced by competing demands, and for a pragmatic reason: fertility histories were not available for all men in the British sample. Unmarried and married respondents were distinguished, because both members of a married couple were asked to specify the help that they gave or received, and because help to parents-in-law was included with help to parents. All analyses were restricted to the respondents who had at least one parent or parent-in-law alive and at least one living child (85 women in the US sample could not be included because of missing data). The resulting sample subsets had 2,304 US and $35^{2}$ British women aged 55-69 years. The relatively small British sample restricted the power of the analyses, particularly of the 72 unmarried women. 


\section{Results}

The analysis proceeded in three steps, beginning with the bivariate associations between providing help to children and to parents among the women with at least one living child and at least one living parent or parent-in-law. Logistic regression was then used to estimate the association between helping a parent and helping a child, having controlled for the covariates. Finally, we fitted multinomial models to identify the factors that associated with (a) helping parents only (relative to helping both parents and children); (b) helping children only, and (c) helping neither parents nor children.

Table I shows the socio-demographic and disability characteristics of the British and US samples and the percentages that provided help to parents or children or to both. In the two countries, the proportion that helped a child was greater than the proportion that helped a parent or parent-in-law, and one-third of the respondents provided help to both. The proportion of helpers was higher among married than unmarried respondents. The American respondents had more children than the British, reflecting the higher fertility in the USA during the relevant years: 64 per cent of US married parents had three or more children, compared with only 35 per cent of the British. There was, however, no difference in the proportion of married parents who had a child still at home, which was surprising but may be associated with the generally younger age of child-bearing in the United States. So although the proportion of US parents with large families was much higher, the proportion with a child aged less than 25 years was slightly lower than in Great Britain. One-half of the unmarried US respondents were divorced, compared with 29 per cent of the British, reflecting its much higher incidence and the later survey date in the US. A slightly higher proportion of the US respondents had non-manual occupational backgrounds, which may be partly explained by differences in the occupational structure and, again, the different dates of the surveys. As noted above, the British and US disability measures differed substantially, but a much lower proportion of the British respondents were identified as having a disability, although a standard and fully comparative measure was not available.

The percentage of respondents that provided help to a parent or parentin-law by whether or not they provided help to a child is presented in part A of Table 2, and the percentage that helped a child by whether they provided help to a parent or parent-in-law in part B. Among married women in Great Britain, and among both married and unmarried women in the USA, those who helped one generation were more likely than those who did not to help the other. In short, a positive association 
T A в L E I. Socio-demographic characteristics of the British and US samples and their provision of help to parents and children

\begin{tabular}{|c|c|c|c|c|}
\hline \multirow[b]{2}{*}{ Variable } & \multicolumn{2}{|c|}{ Great Britain $1988 / 9$} & \multicolumn{2}{|c|}{ USA I998 } \\
\hline & Married & Unmarried & Married & Unmarried \\
\hline & \multicolumn{4}{|c|}{ Percentages } \\
\hline \multicolumn{5}{|l|}{$\begin{array}{l}\text { A. Socio-demographic attributes: } \\
\text { Divorced }\end{array}$} \\
\hline Yes & - & 29.0 & - & 50.0 \\
\hline \multicolumn{5}{|l|}{ Occupational social class } \\
\hline Non-manual & $54 \cdot 5$ & 49.6 & 63.8 & $5^{6.4}$ \\
\hline Manual & $45 \cdot 5$ & 50.4 & 24.7 & 36.5 \\
\hline Missing & - & 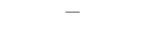 & II. 5 & $7 . \mathrm{I}$ \\
\hline \multicolumn{5}{|l|}{ Disability } \\
\hline None & $73 \cdot 4$ & 6г.9 & $55 \cdot 7$ & 50.6 \\
\hline Some & I6.9 & 20.2 & 29.6 & 26.9 \\
\hline Much & $9 \cdot 7$ & I7.9 & I 4.8 & 22.5 \\
\hline \multicolumn{5}{|l|}{ Number of children alive } \\
\hline One & $\mathrm{I} 9.8$ & 25.8 & 6.8 & II. 6 \\
\hline Two & $45 \cdot 3$ & $35 \cdot 4$ & 28.7 & 29.2 \\
\hline Three or more & 34.9 & $3^{8.8}$ & 64.5 & $59 \cdot 3$ \\
\hline \multicolumn{5}{|l|}{ Ghild(ren) aged less than 25 yrs } \\
\hline No & 72.8 & 8г.9 & $79 \cdot 3$ & 81.3 \\
\hline Yes & 27.2 & I8.I & 20.7 & I8.8 \\
\hline \multicolumn{5}{|l|}{ Ghild(ren) at home } \\
\hline No & 70.9 & 76.5 & $74 \cdot 3$ & 66.8 \\
\hline Yes & 29.I & 23.5 & $25 \cdot 7$ & $33 \cdot 2$ \\
\hline Mean age (s.d.) years & $59 \cdot 3(3 \cdot 7)$ & $60.6(4 \cdot 4)$ & 59.6 & $59 \cdot 9$ \\
\hline Annual income (s.d.) (ooos $£ / \$)$ & $8.6(\mathrm{I} .7)$ & $7.9(\mathrm{I} .4)$ & 10.8 & $9 \cdot 7$ \\
\hline \multicolumn{5}{|l|}{ B. Provide help (money or time) to: } \\
\hline Both parent(s) and child(ren) & 38.5 & 27.8 & 36.1 & 27.3 \\
\hline Parent(s) only & I6.0 & 28.5 & I3.7 & $\mathrm{I} 5.8$ \\
\hline Child(ren) only & 26.8 & 25.8 & 29.9 & 29.8 \\
\hline Neither & 18.7 & I7.9 & 20.3 & 27.1 \\
\hline Sample sizes & 276 & 72 & I,654 & 565 \\
\hline
\end{tabular}

Note: s.d. standard deviation.

between downward and upward between-generation transfers was shown. For example, Table 2 indicates that among British married mothers who were helping a child, 6I per cent also helped a parent, compared with $5^{\text {I }}$ per cent of those who were not helping a child. In the USA, the equivalent percentages were 55 and 40 .

Examined from the opposite perspective, among British married mothers who helped a parent, 69 per cent also helped a child, but among those who were not helping a parent, only 60 per cent helped a child (Table 2). While not all the differences are statistically significant, they indicate a positive association between helping one generation and 
T A B L E 2. Percentage of women that provided help $(A)$ to a parent or parent-in-law by whether they provided help to a child, and $(B)$ to a child by whether they provided help to a parent or parent-in-law

\section{A. Provided help to parent or parent-in-law}

\begin{tabular}{|c|c|c|c|c|c|}
\hline & \multirow[b]{3}{*}{$\begin{array}{l}\text { Helped } \\
\text { child }\end{array}$} & \multirow{2}{*}{\multicolumn{2}{|c|}{ Great Britain I988/9 }} & \multirow{2}{*}{\multicolumn{2}{|c|}{ USA I998 }} \\
\hline \multirow[b]{2}{*}{$\begin{array}{l}\text { Woman's } \\
\text { marital status }\end{array}$} & & & & & \\
\hline & & $\begin{array}{l}\text { Any } \\
\text { help }^{1}\end{array}$ & $\begin{array}{l}\text { Non-money } \\
\text { help }^{2}\end{array}$ & $\begin{array}{l}\text { Any } \\
\text { help }^{3}\end{array}$ & $\begin{array}{l}\text { Non-money } \\
\text { help }^{4}\end{array}$ \\
\hline \multirow{3}{*}{ Married: } & \multirow{4}{*}{$\begin{array}{l}\text { Yes } \\
\text { No }\end{array}$} & \multicolumn{4}{|c|}{ Percentages } \\
\hline & & 6I.2 & $57 \cdot 3^{*}$ & $54 \cdot 7^{* *}$ & $48.0^{* *}$ \\
\hline & & $5^{\mathrm{I} .2}$ & $45 \cdot 9$ & $4^{0.2}$ & $35 \cdot 4$ \\
\hline Sample sizes & & 276 & & & \\
\hline \multirow[t]{2}{*}{ Unmarried: } & \multirow{3}{*}{$\begin{array}{l}\text { Yes } \\
\text { No }\end{array}$} & 54.6 & 53.0 & $47.8^{* *}$ & $4^{0.9} 9^{*}$ \\
\hline & & 6 I.4 & $57 . \mathrm{I}$ & $3^{6.8}$ & $3^{1.5}$ \\
\hline \multirow[t]{3}{*}{ Sample sizes } & & 72 & 72 & $5^{65}$ & 565 \\
\hline & & \multicolumn{4}{|c|}{ B. Provided help to child } \\
\hline & & \multicolumn{2}{|c|}{ Great Britain I988/9 } & \multicolumn{2}{|c|}{ USA I998 } \\
\hline \multirow[t]{2}{*}{$\begin{array}{l}\text { Woman's } \\
\text { marital status }\end{array}$} & $\begin{array}{c}\text { Helped } \\
\operatorname{parent}(\mathbf{s})^{5}\end{array}$ & $\begin{array}{l}\text { Any } \\
\text { help }^{1}\end{array}$ & $\begin{array}{l}\text { Non-money } \\
\text { help }^{2}\end{array}$ & $\begin{array}{l}\text { Any } \\
\text { help }\end{array}$ & $\begin{array}{l}\text { Non-money } \\
\text { help }^{4}\end{array}$ \\
\hline & & \multicolumn{4}{|c|}{ Percentages } \\
\hline \multirow[t]{2}{*}{ Married: } & Yes & $69 \cdot 3$ & $67.8^{*}$ & $72.6^{* *}$ & $48.0^{* *}$ \\
\hline & No & 60.0 & $57 . \mathrm{I}$ & $59 \cdot 5$ & 42.0 \\
\hline Sample sizes & & 276 & 276 & $\mathrm{I}, 654$ & $\mathrm{I}, 654$ \\
\hline \multirow[t]{2}{*}{ Unmarried: } & Yes & 50.7 & 47.9 & $63 \cdot 3^{* *}$ & $3^{8.9}$ \\
\hline & No & 57.6 & $52 . \mathrm{I}$ & 52.4 & $3^{\mathrm{I} .8}$ \\
\hline Sample sizes & & 72 & 72 & $5^{65}$ & 565 \\
\hline
\end{tabular}

Notes: I. Any kind of help to child, any kind of help to parent. 2. Any non-financial help to child, any non-financial help to parent. 3. Money help or help with grandchildren to child; money or ADL help to parent. 4. Help with grandchildren to child; ADL help to parent. 5. Parents or parents-in-law. Significance levels: $* p<0.05 ; * * p<0.01$.

helping the other. The one exception was for unmarried British women, among whom the relationship was negative but not significant. The insignificance of the results in this group and the small sample size suggest that little weight should be given to the reversal.

Table 3 describes the association between helping one generation and helping the other when controlled for a set of covariates. The results indicate that among American women and married British women, helping children positively associated with helping a parent, and vice versa. To restate, the positive association between helping one generation and helping the other was not an artefact of the respondents' age, social class, income, marital status, health and family characteristics. Thus, married 
T A B L E 3. Odds ratios of help to parents/children by whether helped children/parents and by socio-demographic characteristics

\begin{tabular}{|c|c|c|c|c|c|c|c|c|}
\hline \multirow[b]{4}{*}{ Attribute } & \multicolumn{8}{|c|}{ Country, marital status of women, and to whom help given } \\
\hline & \multicolumn{4}{|c|}{ Great Britain I988/9 } & \multicolumn{4}{|c|}{ USA I998 } \\
\hline & \multicolumn{2}{|c|}{ Married } & \multicolumn{2}{|c|}{ Unmarried } & \multicolumn{2}{|c|}{ Married } & \multicolumn{2}{|c|}{ Unmarried } \\
\hline & Parents & Children & Parents & Children & Parents & Children & Parents & Children \\
\hline & \multicolumn{8}{|c|}{ Odds ratios } \\
\hline Gives to children $^{1}$ & $2.13^{*}$ & - & 0.82 & - & I. $76^{* * *}$ & - & I. $79^{* *}$ & - \\
\hline Gives to parents ${ }^{2}$ & - & $2.11^{*}$ & - & 0.82 & - & I. $76^{* * *}$ & - & I. $80^{* * *}$ \\
\hline Age & 0.96 & I.O2 & 0.92 & $0.9^{8}$ & I.02 & 0.98 & $1.07^{* *}$ & 0.9I \\
\hline $\begin{array}{c}\text { Occupation (Ref. } \\
\text { non-manual) }\end{array}$ & I.OO & I.OO & I.OO & I.OO & I.OO & I.OO & I.OO & I.OO \\
\hline Manual & $0.44^{*}$ & I.I7 & I.04 & $2.5^{2}$ & $0.74^{*}$ & 0.88 & I.08 & $0.66^{*}$ \\
\hline Missing & & & & & 0.82 & 0.97 & 0.83 & 0.55 \\
\hline Log income & 0.96 & I.08 & 0.95 & I. $58^{+}$ & I.07 & I. $34^{* *}$ & I. 13 & I.IO \\
\hline Divorced $^{3}$ & - & - & I. 44 & I. 73 & - & - & I. 14 & 0.79 \\
\hline $\begin{array}{l}\text { Disability } \\
\text { (Ref. none) }\end{array}$ & I.OO & I.OO & I.OO & I.OO & I.OO & I.OO & I.OO & I.OO \\
\hline Some & I. 48 & 0.85 & $\{0.67$ & $0.64\}^{6}$ & I.I I & 0.89 & I. $2 \mathrm{I}$ & I.I9 \\
\hline Much & 0.69 & I. $5^{2}$ & $\{0.07$ & $0.04\}$ & I.I 5 & 0.74 & 0.95 & 0.80 \\
\hline $\begin{array}{l}\text { Number of } \\
\text { children (Ref. I) }\end{array}$ & I.OO & I.OO & I.OO & I.OO & I.OO & I.OO & I.OO & I.OO \\
\hline Two & I. 33 & I. 79 & 0.55 & I. 62 & I.OO & I. 38 & 0.78 & I. 32 \\
\hline Three or more & $0.48 *$ & $3.50^{* * *}$ & $0.5^{6}$ & $3.55^{+}$ & 0.95 & I. 49 & 0.76 & I. $6 \mathrm{I}$ \\
\hline $\begin{array}{l}\text { Children aged less } \\
\text { than } 25 \text { years }\end{array}$ & 0.77 & г.6I & - & - & I. $60^{* *}$ & I.I 6 & o.86 & I. $85^{*}$ \\
\hline Children at home ${ }^{5}$ & 0.77 & $2.28 *$ & 0.43 & 3.26 & $0.72^{*}$ & I. $53 * *$ & 0.77 & I.I 8 \\
\hline Sample size & 276 & 276 & 72 & 72 & I, 654 & $\mathrm{I}, 654$ & $5^{65}$ & $5^{65}$ \\
\hline
\end{tabular}

Notes: The results are from a fully adjusted model. Ref. Reference category - for categorical variables specified in the row label. Reference categories for dichotomous variables as follows: I. Does not give to children; 2. Does not give to parents; 3 . Widowed; 4 . No child aged less than 25 years; 5 . No child living at home. Reference Age and log-income are continuous variables. 6 . Because of small numbers, British women with 'much' and 'some' disability have been grouped together.

Significance levels: ${ }^{+}$Marginal significance $p<0.06 ; * p<0.05 ; * *<<0.01$.

British women who provided help to a child were twice as likely to help a parent as those who were not helping a child (and, conversely, those helping a parent were twice as likely to be helping a child). In the US sample, this association was evident among both married and unmarried women, with odds ratios of I.8. A manual-occupational background negatively associated with helping a parent among married women in both countries, while among the Americans, high income positively associated with helping a child. In Great Britain, those with three or more children, and in the USA, those with a child at home, were less likely to provide help to a parent than were mothers with smaller families or no children at home. Rather surprisingly, however, among American married women, having children aged less than 25 years increased the chance of providing 
help to a parent. More expectedly, giving to children positively associated with large family size and, among American unmarried women, with having a child at home.

The results of the multinomial regression model of the probabilities of helping a child only, a parent only, and neither a parent nor a child, in comparison with helping both a parent and a child, are presented in Table 4. This analysis focuses on whether the respondent's age, social class, income, marital status, health, and family characteristics associated with the observed intergenerational exchanges. For example, were those who helped both generations different in specifiable ways from those who did not? The results indicate that having more (potential demands from) children had some effect on transfers to parents. Among British married women, those with three or more children were more than three times as likely to be helping a child only as to be helping both parent(s) and children; while among American women, having more children or a child at home made it less likely that they gave help only to their parents. Surprisingly, having a child aged less than 25 years made it less likely that a women helped children only, but, as is consistent with the results from the logistic regression, less likely to help neither child or parent. In the USA, high income negatively associated with helping only children or only one or more parents; in short, those with high incomes were more likely to be helping both.

\section{Discussion}

The results show that, among mid-life women in two industrialised countries, providing help to one or more adult children increased the probability of also giving help to an elderly parent or parent-in-law, and vice versa. Moreover, a multivariate regression indicated that the positive association between helping one generation and helping the other was not accounted for by the measured socio-demographic characteristics of the respondents. The finding supports the hypothesis that three-generation family solidarity substantially influences transfers of help-put simply, some families are more engaged in intergenerational exchange than others. The analysis permits an extension of the previous understanding about exchanges between two generations, that some families are 'highexchangers' or 'tight-knit', by providing evidence that a similar process characterises three-generation family relationships, at least when transfers by the pivot generation are the guide.

The multinomial regression analysis confirmed that involvement in intergenerational exchanges was not strongly related to the measured 
T А в L E 4. Results from multinomial models: relative risk ratios of helping parents only, children only, or neither ${ }^{1}$

\begin{tabular}{|c|c|c|c|c|c|c|c|c|c|c|c|c|}
\hline \multirow[b]{3}{*}{ Attribute variable } & \multicolumn{6}{|c|}{ Great Britain I988/9 } & \multicolumn{6}{|c|}{ USA 1998} \\
\hline & \multicolumn{3}{|c|}{ Married women } & \multicolumn{3}{|c|}{ Unmarried women } & \multicolumn{3}{|c|}{ Married women } & \multicolumn{3}{|c|}{ Unmarried women } \\
\hline & Parents & Children & Neither & Parents & Children & Neither & Parents & Children & Neither & Parents & Children & Neither \\
\hline & \multicolumn{12}{|c|}{ Relative risk ratios } \\
\hline Age & 0.96 & I.02 & I.04 & I.IO & I.I5 & I.07 & I.OI & 0.98 & I.OI & I.I $2^{* *}$ & 0.95 & I.03 \\
\hline Occupation (Ref. Non-manual) & I.OO & I.OO & I.OO & I.OO & I.OO & I.OO & I.OO & I.OO & I.OO & I.OO & I.OO & I.OO \\
\hline Manual & 0.80 & I. 82 & I. 70 & $0.5^{2}$ & I. $4 \mathrm{I}$ & $0.4 \mathrm{I}$ & I.I5 & I. 35 & I. $53^{* * *}$ & I.I7 & 0.77 & I. 37 \\
\hline Missing & & & & & & & 0.84 & I.09 & I. 29 & 2.15 & I. 39 & 2.32 \\
\hline Log-income & 0.86 & 0.99 & 0.99 & 0.55 & 0.82 & $0.5^{8}$ & $0.72^{* *}$ & 0.90 & $0.70^{* *}$ & 0.83 & 0.83 & $0.78^{*}$ \\
\hline Divorced $^{2}$ & - & - & - & 0.80 & 0.99 & 0.32 & - & - & - & I. 49 & 0.99 & I. II \\
\hline Disability (Ref. none) & I.OO & I.OO & I.OO & I.OO & I.OO & I.OO & I.OO & I.OO & I.OO & I.OO & I.OO & I.OO \\
\hline Some & I.26 & 0.54 & 0.70 & \multirow{2}{*}{$\mathrm{I} .04$} & \multirow{2}{*}{ I.09\} } & 2.64 & I.39 & I.03 & 0.96 & 0.79 & 0.78 & 0.70 \\
\hline Much & 0.20 & 0.82 & I.08 & & & - & I.I3 & 0.75 & I.I 8 & I.09 & 0.93 & I. 29 \\
\hline Number of children (Ref. I) & I.OO & I.OO & I.OO & I.OO & I.OO & I.OO & I.OO & I.OO & I.OO & I.OO & I.OO & I.OO \\
\hline Two & 0.67 & I.I7 & 0.49 & 0.780 & 2.68 & I.05 & $0.45^{*}$ & 0.70 & 0.78 & 0.82 & I. 32 & 0.98 \\
\hline Three or more & $0.4^{6}$ & $3.26^{*}$ & $0.5^{6}$ & 0.37 & 2.95 & 0.56 & $0.5^{*}$ & 0.83 & 0.73 & 0.53 & I.I 4 & 0.83 \\
\hline Children aged less than $25 \mathrm{yrs}^{3}$ & 0.67 & $\mathrm{I} .20$ & 0.75 & - & - & - & 0.84 & $0.62^{*}$ & $0.55^{*}$ & 0.64 & I. 27 & 0.63 \\
\hline Children at home ${ }^{4}$ & 0.35 & I.29 & $0.5^{0}$ & 0.90 & $6.29 *$ & 0.64 & $0.56^{* *}$ & $\mathrm{I} .28$ & 0.93 & 0.88 & I.33 & I.IO \\
\hline Sample sizes & 276 & 276 & 276 & 72 & 72 & 72 & I, 654 & I, 654 & I, 654 & $5^{65}$ & $5^{65}$ & 565 \\
\hline
\end{tabular}

Notes: I. The reference category is helping both parents and children. Reference categories for dichotomous variables: 2. Widowed. 3. No child aged <25. 4. No child living at home. Reference categories for categorical variables are given in the row labels. Age and log-income are continuous variables.

Significance levels: * $p<0.05 ; * * \quad p<0.01$. 
socio-demographic characteristics of the respondents, and additionally indicated that those facing relatively high demands from adult children, notably those with three or more children, tended to curtail help to a parent (Table 4). While these results make only a limited contribution to the specification of the characteristics of three-generation 'high-exchange families', they provide substantial evidence that they exist.

Exchanges of help among three generations will become increasingly important as these family arrangements become more common, and therefore require more research, which will necessarily be intricate and have demanding data requirements. The results presented here point to four important research questions. First, how do intergenerational exchanges change over time, especially in the face of exogenous changes as in the availability of state support? The presented analysis has been cross-sectional, and in the case of Britain on rather old data, although there is some evidence that there have not been major changes since I988, e.g. the proportion of adult children seeing older parents at least once a week was similar in I986 and I999 (Grundy and Shelton 200I). A second problem with cross-sectional data is that it provides only a narrow observation window on the transfers. This has the advantage of enabling the analysis of the concurrent transfers (behaviour) of the pivot generation, but on the other hand, the provision of help is likely to reflect the changing needs of the recipients and the changing situation of the donor, and therefore to be episodic. It would therefore be useful to observe transfers and constraints over a longer period. This would produce a higher estimate of the proportion of the pivot generation that help both ascendent and descendent generation members, and more generally improve our understanding of the dynamics of successive as well as concurrent exchanges of help and support.

Thirdly, future research should focus on the trade-off between helping one generation and the other. As noted earlier, an important constraint on help that involves giving money or spending time is that it involves scarce resources, trade-offs and opportunity costs. Unlike affection or emotional closeness, spending money or time on one generation implies that someone or some others - the other generation, the donor, or their spouse or partner - receives or retains less. What is the relationship between which generation is helped and how much is given? Does a donor to both generations tend to divide equally their beneficence? Does a donor to both generations retain less for her own use? Finally, it would be useful to incorporate measures of the need for help. One of the strengths of the research reported here is that similar results from two countries raise confidence in the findings of a positive association between the provision of help to ascendent and descendent generation members, 
but the interplay between need and the observed help could not be analysed. Consideration of the influence of need will advance the findings reported here.

\section{Acknowledgements}

The research reported here was funded by The Nuffield Foundation. We are grateful to Susan Harris for help with the preparation and analysis of the data.

\section{References}

Agree, E., Bissett, B. and Rendall, M. S. 2003. Simultaneous care for parents and care for children among mid-life British women. Population Trends, I I 2, 29-35.

Attias-Donfut, C. I995. La Solidarité entres Generations: Vieillesse, Familles, Etat [Intergenerational Solidarity: Ageing, Families and the State]. Nathan, Paris.

Bengtson, V. 200I. Beyond the nuclear family: the increasing importance of multigenerational bonds. Fournal of Marriage and Family, 63, $\mathrm{I}-\mathrm{I} 6$.

Bengtson, V., Rosenthal, C. and Burton, L. I99o. Families and aging: diversity and heterogeneity. In Binstock, R. H. and George, L. K. (eds), Handbook of Aging and the Social Sciences. Third edition, Academic, San Diego, California, 263-87.

Berthoud, R. and Gershuny, J. 2000. Seven Years in the Lives of British Families: Evidence on the Dynamics of Social Change from the British Household Panel Survey. Policy, Bristol, Avon.

Bone, M., Gregory, J., Gill, B. and Loder, D. I992. Retirement and Retirement Plans. Her Majesty's Stationery Office, London.

Brody, E. I98I. Women in the middle and family help to older people. The Gerontologist, 2 I, $47 \mathrm{I}-80$.

Disney, R. E., Grundy, E. and Johnson, P. (eds) I997. The Dynamics of Retirement: Analyses of the Retirement Surveys. Research Report 72, Department of Social Security, Stationery Office, London.

Farkas, J. and Hogan, D. 1995. The demography of changing intergenerational relationships. In Bengtson, V., Schaie, K. and Burton, L. (eds), Adult Intergenerational Relations, Springer Publishing Company, New York, I-I8.

Goldscheider, F. K. and Goldscheider, C. I994. Leaving and returning home in 2oth century America. Population Bulletin (Population Reference Bureau, Washington DC), 48, 4 .

Grundy, E. 2005. Reciprocity in relationships: socio-economic and health influences on intergenerational exchanges between third age parents and their adult children in Great Britain. British Fournal of Sociology, 56, 233-55.

Grundy, E., Murphy, M. and Shelton, N. I999. Looking beyond the household: intergenerational perspectives on living kin and contacts with kin in Great Britain. Population Trends, 97, 19-27.

Grundy, E. and Shelton, N. 200r. Contact between adult children and their parents in Great Britain, I986-1999. Environment and Planning A, 33, 4, 685-97.

Henretta, J., Grundy, E. and Harris, S. 200I. Socio-economic differences in having living parents and children, a US-British comparison of middle aged women. Fournal of Marriage and the Family, 63, 852-67.

Henretta, J., Grundy, E. and Harris, S. 2002. The influence of socio-economic and health differences on parents' provision of help to adult children: a British-United States comparison. Ageing \& Society, 22, 44I-58. 


\section{Emily Grundy and Fohn C. Henretta}

Hogan, D. P., Eggebeen, D. J. and Clogg, C. C. 1993. The structure of intergenerational exchanges in American families. American Fournal of Sociology, 98, I428-58.

Litwak, E. and Longino, C. F. Jr i987. Migration patterns among the elderly: a developmental perspective. The Gerontologist, 27, 266-72.

Martin, J. and Elliot, D. I992. Creating an overall measure of severity of disability for the Office of Population Censuses and Surveys Disability Survey. Fournal of the Royal Statistical Society, Series A, I55, I2I-40.

Murphy, M. and Grundy, E. 2003. Mothers with living children and children with living mothers: the role of fertility and mortality in the period igI I-50. Population Trends, I I 2, $36-45$.

Silverstein, M. and Bengtson, V. L. I997. Intergenerational solidarity and the structure of adult child-parent relationships in American families. American fournal of Sociology, ro3, 429-6o.

Soldo, B. J. 1996. Cross pressures on middle-aged adults: a broader view. Fournal of Gerontology, $\mathbf{5}_{\mathbf{I}} \mathbf{B}, \mathrm{S}_{27 \mathrm{I}-3}$.

Speare, A. Jr, Avery, R. and Lawton, L. I99I. Disability, residential mobility, and changes in living arrangements. Fournal of Gerontology: Social Sciences, 46, Si33-42.

US Health and Retirement Study 2004. Sample Sizes and Response Rates (1992-200o). Health and Retirement Study, Institute for Social Research, University of Michigan, Ann Arbor, Michigan. Available online at http://hrsonline.isr.umich.edu/intro/ sho_uinfo.php?hfyle=sample\&xtyp=2 [Accessed I9. I2.2005].

Wolf, D. A. I994. The elderly and their kin: patterns of availability and access. In Martin, L. G. and Preston, S. H. (eds), The Demography of Aging. National Academy Press, Washington DC, I46-94.

Wong, R., Capoferro, C. and Soldo, B. J. i999. Financial assistance from middle-aged couples to parents and children: racial-ethnic differences. Fournal of Gerontology: Psychological and Social Sciences, 54, Si45-53.

Address for correspondence:

Accepted 9 Fanuary 2006

Emily Grundy, Centre for Population Studies, London School of Hygiene and Tropical Medicine, 49-5 I Bedford Square, London WC $\mathrm{W}_{1} \mathrm{~B}{ }_{3} \mathrm{DP}$.

e-mail: Emily.grundy@1shtm.ac.uk 